\title{
Black Women in Higher Education Leadership: A Phenomenolo- gical Research Study Examining Their Utilization of Cross-Race and Cross-Gender Mentorship
}

\author{
Dr. Jerica C. Nickerson-Guidry \\ Lone Star College, USA
}

\author{
*Corresponding Author: Dr. Jerica C. Nickerson-Guidry, Lone Star College, USA
}

\begin{abstract}
Literature has suggested that mentorship is one of the most crucial and influential components for career advancement. However, Black women leaders in higher education are faced with a difficult task of selecting a mentor based on similar characteristics, which leads Black women who are seeking mentoring opportunities to select a mentor of a different race or gender. This phenomenological qualitative study was conducted to understand and describe the lived experiences of cross-race and cross-gender mentorship for a select group of Black women leaders in higher education, using Black feminist thought and intersectionality as the theoretical framework. A purposive sample of eight Black women leaders in higher education participated in in-depth interviews that were video recorded through Zoom. The collected data were transcribed and used to construct four major themes and 11 subthemes through the processes of using initial coding, in vivo coding, and descriptive coding. The major themes included the mentor's contributions, organic connections, relational experiences, and dual role. The findings from this study imply that for this select group of Black women, cross-race only, cross-gender only, or both types of mentoring were pivotal in their professional and leadership development but were not without challenges. The results of this study could encourage individuals faced with the difficulty of identifying and selecting a mentor based on the characteristics of same-race and same-gender to seek out mentors who possess other essential qualities to aid with their career and leadership development and advancement.
\end{abstract}

Keywords: Black women leaders, higher education, cross-race mentoring, cross-gender mentoring, Black feminist thought, intersectionality.

\section{INTRODUCTION}

Mentoring relationships involve rich interpersonal interactions guided by someone (i.e., mentor) who is usually in position of power and wisdom and can effectively guide the path of a person (i.e., mentee) seeking growth and learning opportunities (Humberd \& Rouse, 2016; Kutchner \& Kleschick, 2016). As stated by Johnson and Ridley (2018), mentoring correlates with many personal and career outcomes, such as promotions, increased salaries, upward mobility, enhanced professionalism, increased job satisfaction, peer acceptance, reduced work anxiety, lower turnover rates, improved creativity, and healthier collaborative efforts; these advantages are beneficial for mentees, mentors, and organizations. Although it does not guarantee success, promotion, or progression, the evidence supporting mentorship has been cited as an essential component for an individual's growth and development, especially when mentors and mentees are matched on similar characteristics, such as race and gender (Gardner et al., 2014; Kutchner \& Kleschick, 2016). Additionally, mentoring relationships have been a vital component of many women's professional career advancement and have received a great deal of attention in the research field, especially for those who have been able to secure a mentor based on similarities, such as race and gender (Searby et al., 2015).

However, according to Beckwith et al. (2016), Black women seeking leadership positions often lack influential mentors based on similarities such as race and gender, which contributes to the shortage of Black women in executive positions, particularly in higher education. It is noted that many Black women are highly qualified for leadership positions in higher education, but very few are granted the opportunity to serve in positions such as chancellor, vice or associate chancellor, president, provost and vice president, and dean (Davis \& Maldonado, 2015; Jordan, 2014; Miles, 2012; Wright \& Salinas, 2017). Statistics reported by Gagliardi et al. (2017) in the American College President Study 
2017 revealed that $30 \%$ of presidents in higher education are women and only $5 \%$ of those are Black. The shortage of mentoring has been cited as a crucial reason for women's lack of advancement in leadership (Beckwith et al., 2016; Bynum, 2015; Davis \& Maldonado, 2015), when mentor matching based on similar gender, racial, and cultural background is not always feasible (Tran, 2014). According to Hague and Okpala (2017), it is beneficial for Black women seeking leadership in higher education to identify prospective mentors as those who currently serve or have served as higher education administrators. These mentors will most likely be an individual from a different race or gender based on the statistics revealed by Gagliardi et al. (2017), which stated that 83\% of college presidents are Caucasian, White, or White American and that the typical profile of an American college or university administrator continues to be a White male in his early 60s. It is important to examine cross-race and cross-gender mentorship for Black women leaders in higher education to understand these relationships and their impact on the mentees better.

\section{LiTERATURE REVIEW}

\subsection{Barriers \& Challenges of Black Women in Higher Education}

Research indicates that Black men and women still lag behind in leadership attainment percentages in American higher education and oftentimes face racial discrimination and lack the same opportunities as their White counterparts. Gagliardi et al. (2017) reported a high percentage of college presidents fitting the category of being an older, White male. The challenge in attaining a leadership position for Black women may not stem from being incapable or unqualified but rather from the attitudinal barriers present within the mindset of chief administrators (Cox, as cited in Palmer \& Johnson-Bailey, 2008). Gasman et al. (2015) unveiled an encounter between Amy Gutmann, a White woman and the president of the University of Pennsylvania, and a group of distinguished Black faculty that challenged her academic administrator hiring record and the lack of attentiveness to diversity. Gutmann, in her defense, made a claim about the lack of qualified individuals to fill these positions (Gasman et al., 2015). Gasman et al. (2015) stated the following:

Quite often, the word qualified is used as a euphemism, which allows people to ignore the need for diversity and thus discriminate in hiring. To understand the way qualified is used more fully, consider the phrase "the neighborhood is changing." At this point in American history, most educated people understand that this phrase is a euphemism for "too many Black people [or minorities] are moving into the neighborhood." Oftentimes, the word qualified does not actually pertain to qualifications but instead to fit, with upper-level administrators assessing candidates on the likelihood that they will be pleasant in social situations and hold similar intellectual and cultural views. (pp. 1-2)

Black women are more likely to experience this type of discrimination based on race, gender, social class, and prejudgments (Davis, 2009) even though they are as educationally qualified for these leadership positions in higher education.

One major credential for leadership positions in higher education is an advanced degree (i.e., master's or doctorate degrees). Gasman et al. (2015) indicated that earning an advanced degree is customary for fulfilling executive positions in higher education, yet, despite a substantial increase in the number of Black women with advanced degrees, they remain marginalized in higher education leadership. According to the National Center for Education Statistics, between 2013 and 2014, Black women earned $70 \%$ of master's degrees and $64 \%$ of all doctorate degrees, compared to their Black male counterparts (National Center for Education Statistics, 2017). Although this data confirms that Black women earn more college degrees compared to their Black counterparts, according to Miles (2012), Black men have a significantly higher professional rank than that of Black women. Sanchez-Hucles and Davis (2010) stated that there is current gender bias because society associates men with being natural leaders due to their dominance and assertive masculine traits. Therefore, Black men may only face racial discrimination; however, Black women must overcome both racial and gender discrimination. The absence of Black women in top-tier positions preserves the dominant male culture in leadership, and more Black women need to occupy leadership positions in order to inspire Black women to top-level leadership positions (Sanchez-Hucles \& Davis, 2010). 
Workplace discrimination has also been identified as a contributing factor that hinders the increased visibility of Black women in higher education (Walkington, 2017). Sanchez-Hucles and Davis (2010) argued that White women are able to undoubtedly focus entirely on gender biases and dismiss the recognition of racial discrimination since they tend to identify as the same race of most male leaders. On the other hand, Black women are faced with overcoming the prejudices of being both Black and female, which operates as a site of intersectionality, and have to navigate their identities in order to advance their career in higher education.

\subsection{Mentorship}

Although many individuals intentionally seek out potential mentors to guide them, mentoring relationships often develop in unintentional ways (Hardcastle, 1988; Penny \& Gaillard, 2006), such as networking, organic connections, and dual roles. Career or instrumental mentoring, defined as focusing on the skills and knowledge that are crucial for effective work performance; sponsorship, defined as active advocacy and provides open access to professional networks; and expressive or psychosocial mentoring, which provides emotional support and encourage, have all been proven to be associated with increased self-efficacy and positive career outcomes (Curtin et al., 2016). Many mentoring relationships are comprised of more than one mentor for a mentee, providing a wide range of guidance, experience, sponsorship, and support for mentees who are seeking career advancement (Brown, 2005; Curtin et al., 2016; Evans \& Cokley, 2008; Scanlon, 1997). According to Johnson and Ridley (2018), mentoring correlates with many personal and career outcomes and although the advantages are beneficial for mentees, mentors, and organizations, they are not without barriers.

\subsubsection{Mentoring Characteristics, Behaviors, and Practices}

Mentees tend to prefer proven characteristics, such as the same race and gender, when selecting a mentor (Gardner et al., 2014). However, Hardcastle (1988) concluded some time ago that mentees are also attracted to mentors who are honest, wise, caring, and dedicated to their professions. Penny and Gaillard (2006) opined that mentees should look for mentors who have the ability to identify their strengths and weaknesses, while Shea (1994) stated that mentors should be able to encourage and motivate them to develop professionally; be available, especially when a mentee is in need; be supportive and transparent; be able to maintain consistent contact; show mentees new approaches; listen with empathy; deliberately build a relationship; be informative and aware of existing or emerging opportunities; and be reflective and willing to disclose their own experiences.

Chan et al. (2015) echoed the findings of the past literature presented by Hardcastle (1988), Penny and Gaillard (2006), and Shea (1994), and were able to categorize these characteristics and behaviors into individual, relationship, and institutional/professional/societal dimensions and concluded that the functions within each dimension are reciprocated behaviors in mentoring relationships. Additionally, Johnson and Ridley (2018) highlighted many of the same approaches and characteristics presented by Chan et al. (2015) including accessibility; identify mentees' strengths; recognize/affirm aspirations; model excellence and expectations; guide, direct, and provide opportunities; discuss difficulties; validate mentees' experiences; expose; promote visibility; respect and safeguard privacy; practice cultural humility; appreciate and honor gender differences; provide sponsorship; and be trustworthy.

In addition to the behaviors and practices presented, many mentees secure more than one mentor in order to experience all that mentorship has to offer. Having multiple mentors has been proven to provide a wide range of development opportunities and support for mentees who desire guidance as they climb the leadership ladder (Brown, 2005; Curtin et al., 2016; Evans \& Cokley, 2008; Scanlon, 1997). Although over two decades ago, Scanlon (1997) concluded that women who had several mentors experienced extreme value in attaining their goals; fast forward to almost 20 years later and Commodore et al. (2016) echoed that conclusion by asserting that having a variety of mentors with diverse backgrounds are beneficial for the mentoring experience. Mentees should select mentors at their current institution to help navigate and understand their policies, as well as other institutions and different organizations, so that they are knowledgeable based on a variety of unique circumstances (Commodore et al., 2016). 


\subsubsection{Dual Role Mentorship}

Mentors often do more than provide guidance, sponsorship, and growth for their mentees; many mentors also serve in an additional role such as professor, colleague, or supervisor (Boswell et al., 2017), which produces some unique outcomes for mentees. Scanlon (1997) cautioned against having a supervisor serve as a mentor, regardless of gender, due to the danger that the mentor might become more of a friend and in return jeopardize their jobs when challenges and conflict arise. Meeuwissen et al. (2019) found that multiple-role mentoring relationships experienced conflict; however, they highlighted that the conflict was relatively linked to lack of trust, workplace-based assessment, and having to judge secondary information provided by the mentee. Additionally, it is the thought that a mentor serving in a dual role might provide biased feedback and "serve as a gatekeeper for the profession" (Boswell et al., 2007, p. 5). However, researchers have revealed that dual role mentorship does provide beneficial outcomes. Pan et al. (2011) concluded that mentors who also serve as a supervisor are well-informed of their mentees' career goals and aspirations and are better equipped to provide the opportunities needed within the workplace to enhance their skills and expose mentees to needed networks. As stated by Evans (2019), "In the dual roles of supervisor and mentor, supervisors may have the power to assign leadership roles where other mentors could not. By showing confidence in their employees' abilities, supervisors can support and inspire their leadership skills" (p. 404). Since supervisors who also serve as mentors have an impact on decision making processes, supervisors as mentors can properly guide mentees and can identify and help advocate for leadership opportunities (Evans, 2019).

\subsubsection{Mentorship of Black Women}

Black women experience mentorship differently than their White counterparts and are faced with many challenges from the initiation phase to the dissolution phase; yet, they are able to reap many of the same benefits that mentorship offers (Penny \& Gaillard, 2006). Bova's (1998) study interviewed 14 African American women, who all implied that mentoring was essential to their professional upward mobility; however, securing a traditional mentoring relationship within their organization was challenging due to stereotyping and racism. Yet, a great deal of learning did take place as one of the participants stated, "I learned a lot about White norms and he (mentor) also learned about me in the process" (Bova, 1998, p. 9).

Johnson and Snider (2015) stressed the importance of having a mentor who mirrors "social backgrounds and professional interests" (p. 10) in order to relate to the educational and social challenges faced in higher education. When Black female mentees are granted the opportunity to be mentored by another Black woman, they are able to "learn survival skills such as how to maintain professionalism, dress properly, successfully navigate political environments, and reject negative stereotypes that have been traditionally used to characterize African American women" (Patton \& Harper, 2003, p. 71). However, due to the underrepresentation of Black female faculty and administrators, Johnson and Snider (2015) stated, "White female mentors provided support in terms of helping us gain a better understanding of the gendered roles and responsibilities and changing expectations for women in the field" (p. 11). In addition, their experiences with Black and Latino male mentors were also beneficial in certain ways, such as academic success and career support in which these individuals assisted with creating opportunities to network, attend conferences, participate in speaking engagements, and secure internships (Johnson \& Snider, 2015). In contrast, participants in Patton and Harper's (2003) study expressed how as African American women being mentored by someone of a different race, they often masked their feelings and circumstances so that they would not be perceived as weak and incompetent due to the "fear of being ridiculed, misunderstood, and misjudged" (Patton \& Harper, 2003, p. 73).Although cross-race and cross-gender mentoring can be challenging, they are common and can provide mentees with a wealth of knowledge needed to endure and flourish in educational and professional settings (Bova, 1998; Johnson \& Snider, 2015; Patton \& Harper, 2003).

\section{THEORETICAL FRAMEWORKS}

\subsection{Black Feminist Thought}

Created by Patricia Hill-Collins in 1989, Black feminist thought is a standpoint grounded in the experiences of Black women's everyday struggles (Alinia, 2015). According to Alinia (2015), 
Black feminist thought exposes the way that domination is organized and operates in various domains of power. It also shows the path of struggle and to empowerment, while at the same time highlighting the challenges and difficulties in combating intersecting oppression, since the multipositionality of social agents, on the one hand, and the simultaneity of multiple and intersecting sites of oppression, on the other, make the relationship between domination and resistance highly complex. (pp. 2334-2335)

An assortment of embarrassments and humiliations Black women face has been examined in the context of higher education (Grant \& Ghee, 2015). Therefore, Black feminist thought is relevant to the examination of Black women leaders in higher education and the utilization of cross-race and cross-gender mentorship as it aligns with the goal of allowing Black women administrators to share their lived experiences and reveal their truth. Black women in academia are continuously expressing their significance and value as educated and qualified individuals but are still faced with selecting the voice and stance they will demonstrate once heard and accepted (Grant \& Ghee, 2015).

Black feminist thought as a critical social theory brings an awareness of intersectionality and examines experiences and contributions to empowering Black women, especially Black women leaders in higher education.

\subsection{Intersectionality}

Within Black feminist thought is intersectionality, the connection of gender, class, and race, which was introduced by Kimberlè Crenshaw (Moradi \& Grzanka, 2017). Crenshaw (1989) introduced this term over 30 years ago "to describe how Black women's experiences of the unique combination of racism and sexism were obscured by treating race and sex discrimination as separate matters in U.S. law and in feminist and antiracist activism" (Moradi \& Grzanka, 2017, p. 502). In an interview with Steinmetz (2020) of TIME magazine, Crenshaw clarified the following regarding intersectionality and its modern-day use of the term:

These days, I start with what it's not, because there has been distortion. It's not identity politics on steroids. It is not a mechanism to turn White men into the new pariahs. It's basically a lens, a prism, for seeing the way in which various forms of inequality often operate together and exacerbate each other. We tend to talk about race inequality as separate from inequality based on gender, class, sexuality, or immigrant status. What'soften missing is how some people are subject to all of these, and the experience is not just the sum of its parts. (p. 82)

Crenshaw continued to advocate for the fact that "intersectionality is simply about how certain aspects of who you are will increase your access to the good things or your exposure to the bad things in life" (Steinmetz, 2020, p. 82). Intersectionality is generally used as an analytic tool to address discriminatory barriers faced by marginalized individuals (Collins \& Bilge, 2016). According to Stitt and Happel-Parkins (2019), "When intersectionality is ignored, researchers discount the experiences of individuals who may be affected by more than one of these categories, thereby silencing their voice by not understanding the nuanced ways that different identity categories influence lived experiences" (p. 63). By ignoring the intersection of race, class, and gender, generally, Black women have had to choose between one of the categories they want to primarily identify with because society has crucified those who have stood before the masses and demanded to be known as both Black and female (Stitt \& Happel-Parkins, 2019). By forcing Black women to stand in this crossroad and choose, many Black women continue to experience oppression and miss opportunities due to the lack of understanding of how race, class, and gender overlap (Lewis et al., 2017). As it relates to mentoring, intersectionality can provide insight into how race and gender effect mentors' identities and how they mentor mentees (Mondisa, 2014).

The advances of Black feminist thought and intersectionality have disclosed Black women's distinctive experiences of exclusion, oppression, resistance, discrimination, and empowerment between self, society, and social structures (Alinia, 2015; Grant \& Ghee, 2015; Moradi \& Grzanka, 2017). Research has shown that Black women do not experience race, class, gender independently, but that these categories are interwoven and act as one barrier that has suppressed Black women's ability to break through (Crenshaw, 1989; Grant, 2012) the glass ceiling (Davis\& Maldonado, 2015). 


\section{Method}

To better understand the description, characteristics, and behaviors/practices of cross-race and crossgender mentorship for a select group of Black women in higher education leadership, phenomenological qualitative research was used to conduct this study. Mapp (2008) emphasized that phenomenology searches for meanings and essences of lived experiences and finds descriptions through first-person accounts during one-on-one interviews. Phenomenological research allows for the use of interpersonal interviews to ask open-ended questions and probe for in-depth responses about participants' lived experiences, perceptions, barriers, and knowledge. Wilson and Washington (2007) highlighted how phenomenology is considered to be a suitable and comprehensive approach for conducting research with African American women.

According to Moustakas (1994), when choosing to conduct a phenomenological study, researchers must first overcome the challenge of selecting a topic and question that has not only social meaning but also personal significance. Due to the nature of the small representation of Black women in higher education leadership and the effectiveness of mentorship regarding career advancement, examining cross-race and cross-gender mentorship holds both social meaning in terms of examining a viable option for Black women seeking leadership in higher education, as well as personal significance being that I am a Black woman in higher education, who desires to climb the leadership ladder. Additionally, researchers need to examine the types of phenomenology that will benefit the study and production of valuable results in which the interpretive process will yield significance based on participants' lived experiences (Moustakas, 1994).

The type of phenomenology that served this study best was Moustakas' (1994) interpretation of Edmund Husserl's transcendental or psychological phenomenology. Moustakas (1994) stated, "Husserl's transcendental phenomenology is intimately bound up in the concept of intentionality," which refers to being cognizant and mindful to participants' lived experiences and the ability to "recognize that self and the world are inseparable components of meaning" (p. 27). Creswell and Poth (2018) opined that transcendental phenomenology focuses more on narratives disclosed by participants and less on the analyses of the researcher. It is also imperative for researchers to refrain from incorporating their experiences and approaching the phenomenon with a fresh perspective, which is known as epocheorbracketing (Creswell \& Poth, 2018). A phenomenological researcher must recognize and reject any personal experiences and biases relating to the phenomenon of the study and remain objective to allow the essences of participants' lived experiences to emerge.

\subsection{Population and Sample}

Participants in this study were required to have experienced the phenomenon being explored, which is cross-race only, cross-gender only, or both cross-race and cross-gender mentoring and were able to effectively describe their past and present experiences (Creswell \&Poth, 2018). The criteria for key participants, Black women in higher education leadership, in this study included those who (a) have earned a master's or doctoral degree, (b) currently work in four-year or two-year institutions in the USA, serving in positions of a dean or higher, and (c) who have utilized cross-race only, cross-gender only, or both cross-race and cross-gender mentorship as a tool to or in hopes of advancing their career.

In phenomenological research, scholars believe that studies should have at minimum three participants (Englander, 2012) and focus more on quality than the quantity of the sample size and detailed account of each participant's experience (Smith et al., 2009). For a phenomenological study, participants may or may not be located at a single site, but more importantly, participants need to have all experienced the phenomenon and be able and willing to accurately explore and express their lived experiences (Creswell \& Poth, 2018).

\subsection{Data Collection and Analysis}

Approval from Abilene Christian University's Institutional Review Board (IRB) was granted in February 2020. Shortly thereafter, 42 Black women in higher education leadership were contacted by email soliciting participation in this study, based on recommendations and institutional websites. Seventeen potential participants replied to the email; however, only eight met the criteria and confirmed a scheduled date and time for their interview (see Table 1). 
Black Women in Higher Education Leadership: A Phenomenological Research Study Examining Their Utilization of Cross-Race and Cross-Gender Mentorship

Table1. Demographics of Participants

\begin{tabular}{|c|c|c|c|c|}
\hline $\begin{array}{l}\text { Participant's } \\
\text { Assigned } \\
\text { Pseudonym }\end{array}$ & Leadership Level & Type of Institution & $\begin{array}{c}\text { Highest Level of } \\
\text { Attained } \\
\text { Education }\end{array}$ & $\begin{array}{l}\text { Number of Cross-Race } \\
\text { Only, Cross-Gender } \\
\text { Only, and/or Cross- } \\
\text { Race and Cross-Gender } \\
\text { Mentors Discussed }\end{array}$ \\
\hline Melissa & President & Two-year college & Doctorate & 4 \\
\hline Sara & Dean & Two-year college & Doctorate & 1 \\
\hline Chloe & Vice President & Two-year college & Master's & 1 \\
\hline Elizabeth & Vice President & Two-year college & Doctorate & 4 \\
\hline Jennifer & Vice President & Two-year college & Doctorate & 3 \\
\hline Kennedy & $\begin{array}{c}\text { Executive } \\
\text { Director }\end{array}$ & Two-year college & Master's & 2 \\
\hline Brittany & $\begin{array}{l}\text { Executive } \\
\text { Director }\end{array}$ & Two-year college & Doctorate & 2 \\
\hline Ashley & Chief of Staff & $\begin{array}{c}\text { Four-year university } \\
\text { system }\end{array}$ & Doctorate & 3 \\
\hline
\end{tabular}

Semi structured, open-ended questions were designed to elicit participants' lived experiences with the phenomenon. Video interviews, based on all participants' preference and approval, was used to collect and digitally record the data. Each interview was scheduled to last up to two hours to ensure questions were answered thoroughly; most of the interviews lasted between 40-80 minutes in length.

While analyzing the data and constructing themes from the participants' responses, it was essential that participants were assigned a pseudonyms when reporting the data, as protection of the participants should include researchers masking their participants names early in order to avoid the presence of identifiable information in the analysis files (Creswell \& Poth, 2018). The themes were created through a process of coding, condensing the codes, and presented in the findings section. Rubin and Rubin (2012) stated that coding involves thoroughly categorizing concepts, themes, events, and topical markers so that the researchers can easily retrieve and assess all the data that discusses the same subject across all interviews. Initial, in vivo, and descriptive coding were used to analyze the interviews, "extracting general and unique themes from all of the interviews and making a composite summary" (Groenewald, 2004, p. 50).

Initial coding is an open-ended approach to coding in which the researcher codes for their "first impression" words or phrases; it's an opportunity for the researcher to begin to deeply reflect on the contents of the data, break it down into discrete parts, and examine them for similarities and differences (Patton, 2015). In vivo coding when a code is taken verbatim directly from the data and placed in quotation marks and is particularly well suited for extracting and highlighting indigenous terms or jargon (Ivankova, 2015). Descriptive coding is considered to be a straightforward approach used to assign basic, descriptive labels to data that will provide a portfolio of topics (Patton, 2015). It summarizes the primary topic of the excerpt in a word or short phrase and is often retained as a first step in the data analysis, which is considered a good technique for beginners (Ivankova, 2015). Each of these coding passes helped to provide awareness and expound the meaning, structure, and essence of the phenomenon.

\subsection{Limitations}

Limitations are beyond the control of researchers and have the potential to affect the generalizability of the results, such as incorrect contact information, time limit restrictions placed on the interviewer by the interviewee, lack of elaboration in interview responses, misinterpretation of interviewees' responses, and inability to validate the realness of their lived experiences. One limitation was that some participants requested face-to-face interviews in their initial email response when agreeing to participate, but due to the COVID-19 pandemic, all interviews had to take place via Zoom video conferencing. This possibly caused distractions for participants including interruptions from family, pets, emergency calls, and unidentified external noises. Additionally, some interviews were interrupted due to lost and slow internet connections. Although, interviews reconvened once connection was established, this limitation possibly interfered with participants' initial thoughts and answers. In addition, slow internet connections caused the video interview to be pixelated, with 
delayed audio. Participants were asked to repeat information when this occurred; however, it is impossible to determine if the initial thoughts, again, were shared.

Lastly, most of the participants were able to describe more than one mentor. In answering the interview questions, although participants were asked clarifying questions, it is possible that they did not align examples/stories/narratives with the correct mentor they were discussing. Many of the participants emphasized and focused on one particular mentor more than other mentors, for unknown reasons, which potentially impacted the validity, analysis, and interpretation of participants' lived experiences with the phenomenon.

\section{FINDINGS}

The findings highlight a select group of Black women in higher education leadership and their lived experiences with cross-race only, cross-gender only, or both cross-race and cross-gender mentorship. Data analysis revealed four overarching themes and two to three sub-themes for each (see Table 2). All eight participants $(100 \%)$ made statements that formed the basis of all four themes and most of the sub-themes. Each overarching theme and sub-theme offered an understanding of cross-race only, cross-gender only, and/or both cross-race and cross-gender mentorship.

Table2. Overarching Themes and Subthemes

\begin{tabular}{|c|c|c|c|}
\hline $\begin{array}{c}\text { Mentor's } \\
\text { Contributions }\end{array}$ & $\begin{array}{c}\text { Organic } \\
\text { Connections }\end{array}$ & $\begin{array}{c}\text { Relational } \\
\text { Experiences }\end{array}$ & $\begin{array}{c}\text { Dual } \\
\text { Role }\end{array}$ \\
\hline Vision and Outlook & $\begin{array}{c}\text { Transparent and } \\
\text { Communicative }\end{array}$ & $\begin{array}{c}\text { Connections Based on } \\
\text { Race and/or Career Paths }\end{array}$ & $\begin{array}{c}\text { Supportive and Willing } \\
\text { to Invest }\end{array}$ \\
\hline $\begin{array}{c}\text { Ability to Guide, } \\
\text { Advocate, and/or } \\
\text { Sponsor }\end{array}$ & Trust and Rapport & $\begin{array}{c}\text { Inability to Relate Based } \\
\text { on Race, and/or Gender } \\
\text { Differences }\end{array}$ & $\begin{array}{c}\text { Frequent and } \\
\text { Convenient Meetings }\end{array}$ \\
\hline $\begin{array}{c}\text { Network and Exposure } \\
\text { Opportunities }\end{array}$ & Personable & & Problematic and Risky \\
\hline
\end{tabular}

\section{Theme1: Mentor's Contributions}

Each participant discussed the positive contributions made by their mentors throughout the mentoring relationship. As each participant shared their lived experience, they all discussed how their mentor(s) displayed (a) vision and outlook, (b) the ability to guide, advocate, and/or sponsor them, and (c) network and exposure opportunities.

Subtheme 1: Vision and Outlook. Six participants (75\%) emphasized their mentor's ability to have a vision and an outlook regarding their career path and trajectory. For Melissa, it was evident to her that she would reach the pinnacle and become a college president. However, for the other seven participants they all talked about how a mentor saw something in them that they necessarily did not see in themselves. Elizabeth and Brittany both shared how their mentors have caused them to think bigger and to reach for upper-level, senior administrative positions. Elizabeth stated, "As I started off in higher education and got my first leadership position in enrollment management, I thought I'd made it and wasn't much else to shoot for. My White male mentor saw and thought otherwise."

Sara shared how her Black male mentor pushed her beyond the limitations she'd placed on herself early on in her career, which ignited the thought of career advancement. She stated:

We all self-doubt sometimes, but when I would do it while in his presence, he would immediately stop me right in my tracks and tell me how great of a leader I was and how I could do any job within the institution especially vice president. It was during moments like that that I started thinking about becoming a dean and even a vice president.

Kennedy's Black male mentor also envisioned more for her and has constantly encouraged her to groom her leadership skills by suggesting different leadership institutes and as she recalled "proposing that I can in fact be a college president." 
Subtheme 2: Ability to Guide, Advocate, and Sponsor. All participants were able to vividly recall their mentors at some point providing guidance, advocacy, and sponsorship. Ashley was adamant about stating, "A lot of times your mentors don't have to be directly in the career you're in because guidance and leadership seem to have the same process in how one develops and matures, based on my experience." Jennifer, Kennedy, and Ashley alluded to the idea that mentors should not only have a vision for their mentees but also be willing to guide them down their career path. Melissa enthusiastically discussed how appreciative she was of her White female mentor and "the guidance of giving insight into White spaces and the interview process, especially knowing that those interview rooms would be occupied by the majority of White people."

Chloe disclosed that since her White male mentor recognized that there were areas where he could not help in, he sought out training and development programs for her to attend and would cover the costs and fees. Elizabeth mentioned how sponsorship can be as simple as someone recommending you at any moment and Sara echoed that statement by stating that her Black male mentor was the first person to throw her name into the recommendation bowl when an interim leadership position became vacant.

Subtheme 3: Network and Exposure. As Elizabeth continued to discuss how her mentors also sponsored her, she quickly transitioned into how network and exposure opportunities were created by one of her mentors. She stated:

She was doing an invitation-only luncheon with a keynote speaker. She's like, oh, you're coming to my invite-only and you're sitting at my table in the front with all the big names that are here. We've got to get your name known so that as you advance and start thinking about becoming a president, you have access to others for reasons that aren't even known yet. Now mind you, I hadn't said a word about becoming a president. I'd just gotten into enrollment management.

Melissa stated how her White female mentor has put her in places and positions that have produced positive outcomes and have connected her with individuals along the way that has increased her network. Additionally, Jennifer emphasized the exposure within itself to have a mentor other than a Black woman. She discussed how having access to cross-race only and both cross-race and crossgender mentorship exposed her to different leadership styles and qualities of people in general. It was beneficial for her to experience the perspective of a cross-race/crossgender mentor to better understand how people navigate situations, not just based on stereotypical men or women's actions.

\section{Theme2: Organic Connections}

Chloe shared how the mentoring relationship with her White male mentor was an organic process. Although he was her supervisor and they had already worked closely together, she did allow the mentoring component to "take its course." Although she noticed "mentoring moments happening," she was intentional about not forcing it. Although Melissa, Jennifer, and Ashley did mention the use of various leadership programs that formally created mentoring opportunities for them, they all emphasized the importance of having the mentoring relationship blossom genuinely and organically.

Subtheme 4: Transparent and Communicative. The participants stated that open, honest, and transparent communication was not only important to them but also carried out by their mentors. Melissa recalled a mentoring moment with one of her Black male mentors and how she wanted candid feedback, "but at the time he got down and dirty with it." He was so transparent that she stated she "had to grow thicker skin" because if she truly wanted to work with him, which she did, "he was going to tell it like it is." Jennifer discussed a "huge lightbulb" moment for when she asked her Hispanic male mentor about a decision that was made during a hiring process and a committee she did not serve on. She did not understand why the candidate was selected, so as to both her supervisor and mentor, she wanted him to help her understand. She stated, "In his ability to be truthful and say he wasn't thinking five, 10 years from now but that he was just trying to get through year one and three and the person they selected, they believed, would get us there."

Subtheme 5: Trust and Rapport. Not only did Jennifer's Hispanic male mentor demonstrate transparency when she asked him about a hiring decision that was made, but she also shared another instance in which their trust was tested and strengthened. She shared the story of one of her family members, who was an employee at the institution she and her mentor worked at, and how her family 
member had done something extremely bad. The Hispanic male mentor gave her the "liberty of disclosing the situation and outcome privately by pulling me to the side and not in an executive meeting where he had every right to do so." After this particular instance, she gained another level of trust because "he not only handled it privately but shielded that situation from becoming campus news, meaning campus gossip, and protected my reputation, knowing that I was affiliated with that individual as a family member." She added, "I appreciated his level of consideration and I think it allowed me to trust him as a person, both professionally and personally, a lot more. I think having that relationship with him helped me have those honest conversations."

Melissa emphasized the importance of trust. However, she did stress that this took time. When comparing this approach to one of her Black male mentors, she stated:

With him, it probably took a good third time we had our conversation for trust to be there and this was like within a few weeks. He demonstrated trust for me immediately and I'm not sure if it's because we were able to relate to one another's Blackness. However, with the White female mentor, it took a little longer. I'd been burned one too many times by a White administer and I had my guard up in spite of what she said.

In addition, Chloe, Kennedy, and Ashley all screamed, "Trust!" when asked about behaviors and practices that strengthened and weakened their mentoring relationships.

Subtheme 6: Personable. Chloe, Elizabeth, and Jennifer directly stated how personable their mentors were, which enhanced their connection. Others used words such as "good-hearted, "relatable," "charming," and "likable" in the same regard. As Elizabeth revealed experiences and observations of her White male mentor, she stated, "For him, you don't need to tell people his title because you feel it once he enters a room. People should feel your presence. He's so personable that when he walks in a room you just know he's the [college] president, but you also quickly realize how approachable and down-to-earth he is." Jennifer recalled a campus visit she took with her Hispanic male mentor where he previously worked and was at least five years removed, but how they "literally could not walk the campus because everybody who seen him wanted to stop and hug him and talk to him."

\section{Theme3: Relational Experiences}

Based on participants revealing their cross-race only, cross-gender only, and/or both cross-race and cross-gender mentoring relationship, all shared some similar experience when analyzing the type of mentoring relationship and the ability and inability to connect and relate, based on race and gender differences, as well as career paths.

Subtheme 7: Connections Based on Race and Career Paths.Each participant acknowledged that in order for a mentoring relationship to be initiated and carried out, there must first be a connection. Melissa stated how important it was for her to align herself with individuals who not only had vision but who were also a person of color. This was not only important for her, but her White female mentor as well because she knew she could not mentor her on that level and when issues centered on race would arise. Ashley echoed this notion by stating the connection with her Black male mentor has been an essential asset to her growth and development simply because they are able to share some experiences that stem from being Black, and although he is a Black male, he still has a sense of understanding in such a way that he can make what he is saying resonate.

For Melissa, Chloe, Elizabeth, Jennifer, Brittany, and Ashley, they all expressed a career path connection with mentors who were not Black. Precisely, each one of them shared how the mentoring relationship matured due to the mentor having experience in their aspired or current leadership position. Brittany stated, "I needed someone who traveled the path I am currently on." Elizabeth added, "Having a mentor who is familiar with what it takes to reach the top and has reached the top themselves is almost a requirement for any person that wants to be successful, no matter what the goal is." Jennifer even mentioned, "Having a mentor who has not only succeeded but also failed at some point humanizes this journey. At times, I feel like I have to be Superwoman and invincible when in actuality, no man nor woman is." She affirmed that her White male mentor constantly shares his journey with her as a way to encourage her and it has been inspirational to realize how much they do have in common and how his experiences, as he ascends to the top, have been nothing short of admirable. 
Subtheme 8: Inability to Relate based on Race and Gender. All participants who discussed a White mentor revealed their mentors' inability to relate to them based on race. Chloe recalled at the beginning of her mentoring relationship with her White male mentor, she struggled with accepting that "it's not his experience" when she would seek guidance from him.Elizabeth revealed some struggles she faced with her White male mentors and combined the inability for them to connect based on race and gender. She stated:

There are things that they shared with me that work easily sometimes for White men and I just had to take that later, process it, figure out how to massage this for me because how it worked for them is not completely how it's going to work for me. I just know that the process is still what the process is, but it just might mean there's a little divot in it that I have to adjust for because when I walk into a room, I'm not racially ambiguous. There's no could she be Black? No, I am. So, their advice would not always be something that served me best because I am Black, and I am also female.

Each participant with a White mentor, whether male or female, discussed similar challenges that Chloe and Elizabeth faced in regard to being a Black woman. Seven participants revealed that their White mentors recognized their inability to relate to them based on race. To fill this gap or disconnect, their White mentor(s) recommended to them, and some even invested in, a membership, program, or conference that specifically focused on Black leaders' development. Melissa stated that her White female mentor's suggestion and investment to attend the Lakin Institute for Mentored Leadership for African American leaders serving in senior-level administrative functions at community colleges, where she met (and discussed in this study) one of her Black male mentors, exceeded her expectations and allowed her to connect with other Black people in higher education. Chloe, Elizabeth, and Ashley all shared that their White male mentors actively and continuously searched for training and development opportunities that specifically highlighted Black women as leaders since they could not relate to them in most instances.

Kennedy and Ashley were the only ones to reveal specific gender differences. Kennedy stated that she and her Black male mentor recognized their shared limitations early in the relationship. She stated, "We both acknowledged that as a male, there were things that he could do that I necessarily couldn't do because I'm a female." She shared an example in which he was trying to advise her on what to do while faced with a certain issue, but how they "kept hitting roadblocks because the angle he was coming from, was more acceptable coming from a man." From that example, she was referring to initial suggestions that were described as being "aggressive" and "assertive," but that their leaders and work environment would not accept that type of approach from a female, less a Black female, because it would mostly likely create a "hostile and uncomfortable environment" for their White colleagues. Ashley extensively discussed the gender differences that were present in her mentoring relationships. She stated:

My male mentors conduct a lot of their business in very different places, for example, football games, golf courses, and late-night dinners at high-end restaurants. I have been invited to those networks and settings, but my reality is I am a wife and a mother. I have to choose career or family and my family comes first. So, when these meetings would happen after work hours, I would either have to stay briefly just to show my face and be introduced or decline the invitation. By the time I would leave, if I was able to attend, the real business wouldn't have even started yet. So, because I am a wife and a mother, I'm not able to stay to most dinners' or events past 8:00 PM or attend a golf session on a Saturday or Sunday because that's family time. My son and my husband also have expectations of me because of my role in their lives. So, it becomes frustrating because for my male mentors and even for my husband, there are some behaviors that they can demonstrate that are more acceptable because they're men. Even for someone on the outside looking in, if they see me too engaged with my male mentors, the narrative becomes 'she's sleeping her way to the top.' That's unfair to me because if the roles were reversed, that never becomes the narrative for the man.

Brittany briefly discussed some behavioral differences that she observed with her White female mentors and how certain actions, such as challenging an authoritative leader, would be viewed as being "passionate," whereas her approaches "would be viewed as being an angry Black woman" from others. 


\section{Theme4: Dual Role}

All participants revealed that the mentors disclosed in this study have served them in another role. By having a dual title, the participants revealed subthemes including a) supportive and willing to invest, b) frequent and convenient meetings, and c) problematic and risky.

Subtheme 9: Supportive and Willing to Invest. Due to the nature of these mentoring relationships, participants revealed the amount of support received and their mentors' willingness to invest in them. Melissa obtained her White female mentor by securing the position of vice president and provost at the institution the White female mentor was the president of at the time. Since Melissa had the goal of one day becoming a college president, it was refreshing for her to have that support of not only her supervisor but also someone she could learn from as a mentor. Chloe stated how based on the qualities that she saw in her vice president/supervisor, ignited the desire to want to be mentored by him: "I was very intentional about who I wanted to mentor me. I looked for certain qualities and over the years, my supervisor had not only demonstrated but also executed the qualities and skills I was looking for in a mentor," she stated. As the mentoring relationship grew, so did his support of her advancing to the next level and equipping her to be able to do so.

The participants whose mentor also served as a supervisor interchangeably used the words "sponsor" and "invest" that either demonstrated the mentors" will and action to financially sponsor or invest in their career and leadership development by either paying for their membership, program, and conference fees or being that reference that is needed in order to get to the next level. Jennifer mentioned of her Hispanic female mentor:

She had a certain budget that she had to use each year, and she told me that whenever I needed funds to cover a conference I wanted to attend or an institute I found to be beneficial, she would just pull the monies from that budget and sponsor it. She didn't have to do that for me, and I noticed that she really didn't do that for anyone else. When I mustered up the courage to ask her why she is eager to do it for me and not someone else, she'd simply say, "Because you got it. You got what it takes to excel, and I know you will. I have a strong desire to get you where you want and need to be because leaders, with your potential, don't come around too often. Besides, I know you'll attend these conferences and things of that nature and will actually learn something, come back, and apply it. Others will simply see it as a free trip and a vacation." Because of this transparency and level of trust, I knew I had her support and didn't take it for granted.

Subtheme 10: Frequent and Convenient Meetings. All eight participants shared a dual role with their mentor, whether it was supervisor, colleague, or professor and all participants stated how the latter role made meetings with their mentors more frequent and convenient. As Chloe discussed her White male mentor's support and will to invest, she also discussed her appreciation of his time. She stated:

He took a lot of extra time with me. I had a normal one-on-one with him, but he also allowed me to come in early so that he and I could meet before the department actually got going. In those moments, I could share whatever I was needing extra help with or he would share things with me that I needed to know as a future leader.

Sara and Brittany shared that since their mentors were also their colleagues, they frequently found themselves engaging in mentoring discussions as the casual conversation took place. As Sara revealed her experience with her Black male mentor she stated, "It's almost like I had a mentoring moment daily, which I probably wouldn't have gotten had he been in a leadership role." Participants engaged in frequent and convenient meetings both formally and informally with their mentors and received "nuggets" and "useful pointers" that aided their success as leaders.

Subtheme 11: Problematic and Risky. Although for the participants, it seemed to be beneficial for their mentors to also serve as their supervisors or colleagues, it was also revealed to be problematic and risky for five of them. When Melissa discussed one of her Black male mentors and her Middle Eastern mentor, which were her president and vice president at the time, she shared that those mentoring relationships did not last long, and it was because of the dual role. As she continued to discuss them, she said, "As I now talk about them, I don't really think they fit the description of 
mentorship." However, she continued to share her experience with them because at the time, she did consider them to be her mentors. When discussing both men, she shared how they both wanted her to stay in a certain position for five years and that they would eventually make a deal with her. However, she felt as though she did not need five years to be in one position before she could advance her career. She said, "They were both looking out for themselves. A real mentor wouldn't and shouldn't do that and it wasn't revealed to me until I experienced the mentoring relationship with my White female mentor." When discussing her White female mentor, however, Melissa stated, "Sometimes it would be hard because I didn't always agree with some of the decisions that she made as my supervisor."

Ashley discussed the difficulties she faced with her White male mentor and one of her Black male mentors. To summarize her experience with the dual role, she stated:

They're men and by also being my supervisors, rumors started to spread that I was sleeping with them. The fact that I worked with the White male mentor in a government capacity and the Black male mentor in higher education just goes to show how gender and sex differences exist. What made it more taxing was that I had to go to work every day knowing that my reputation was on the line. However, since I knew that there was nothing more going on between neither man, I took that risk and to this day allow them to mentor me because of the capital they bring being mentors.

The dual role theme for participants revealed beneficial and detrimental aspects of the mentoring relationship. However, each participant confirmed that none of their mentoring relationships were dissolved or have been dissolved due to any of the examples they disclosed.

\section{Discussion, CONClusions, AND Recommendations}

Eight participants described their lived experiences with cross-race, cross-gender, and/or both types of mentorship in many ways any mentoring relationship might be experienced. They found their mentors to care about and be invested in their leadership development and professional success. They also described connections they had with their mentors that were based on the mentors' leadership qualities, career paths, and professional experiences that the mentor shared with them within the context of the mentoring relationship. Their description echoed Johnson and Snider's (2015) depiction of having a mentor who mirrors "professional interests" (p.10), as well as Johnson and Ridley's (2018) recommendation to select a mentor based on characteristics such as social skills, communication skill, short- and long-term career goals, and desired career trajectory, which benefited their career outcomes in a positive way. One of the participants stated, "I recognized the qualities my Hispanic male mentor had that I wanted to achieve, which is one of the reasons I wanted him to mentor me."

Almost all the participants discussed having more than one mentor and deemed it beneficial due to the various qualities each mentor possessed. This supports the assertion that having multiple mentors provides a wide range of development opportunities and increased support (Brown, 2005; Curtin et al., 2016; Evans \& Cokley, 2008; Scanlon, 1997). Participants in this study gained mentors at their workplace, as well as from other organizations, which illustrates Commodore et al.'s (2016) assertion that mentees should select mentors at their current institution, as well as different organizations. Additionally, the participants found their mentors to be helpful in connecting them to other resources when they found themselves unable to help the participants in the particular ways they needed. This finding echoes Kent et al.'s (2015) conclusion that found cross-race and cross-gender mentorship to be valuable for mentees based on the ability to establish networks, secure resources, increase knowledge, and navigate the tenure and promotion process.

Most of the participants described experiences with mentors who were also their supervisors. Although Scanlon (1997) advised against this, to a large extent, the study's participants experienced satisfaction and gratification with their mentor's dual role. This allowed them to see their mentors in action and to experience their mentor's leadership styles first-hand. Additionally, the participants shared how their dual role mentors were aware of their career goals and how they were instrumental in helping them achieve those goals, which supports Pan et al.'s (2011) assertionthat mentors who also serve as a supervisor are well-informed of their mentees' career goals and aspirations and are better equipped to provide the opportunities needed within the workplace to enhance their skills and 
expose mentees to needed networks. The participants did experience both positive and negative aspects of having a mentor with this dual role. They benefitted from the fact that their mentors who also served as their supervisors obviously valued their professional development and were motivated to invest in them. Many of the participants shared experiences where their mentors recommended and funded their attendance and participation at various conferences, institutes, and programs that aided in their continuous professional development efforts.

The participants also described experiencing other unique benefits of being mentored by someone of a different race and/or gender. Several found their White mentors to be better-connected to people and opportunities, compared to their mentors of another race. They described their White mentors inviting them or helping facilitate ways for the participants to earn a "seat at the table" to help them advance in their careers. One participant stated, "My White male mentor was well-connected and very active in many professional associations." This seems to have helped, as the participants with White mentors described making greater professional strides due, in part, to their experiences with this increased access and social connection. Another participant made an assertation that revealed the significance of having a White mentor by stating, "He was very responsible for one of the appointments I received," later mentioning that her Black male mentors were not as connected as the White male mentor and how they were not able to "pull a few strings" like the White male mentor did. These findings are in agreement with Palmer and Johnson-Bailey's (2008) research that found Black female participants from corporate settings benefitted more from White male mentoring. Thus, Palmer and JohnsonBailey (2008) concluded that White males tended to be more effective mentors, given their power and rank in organizations and their ability to direct the mentee through organizational politics.

The participants also described some difficult experiences connecting to their mentors based on matters relating to race and/or gender, hence, the presence of Black feminist thought and intersectionality in which these theoretical frameworks show "the path of struggle and to empowerment, while at the same time highlighting the challenges and difficulties in combating intersecting oppression" (Alinia, 2015, p. 2334). For most of the participants, their mentors recognized the challenges they encountered being both Black and female; however, the mentors had difficulty providing practical guidance to help them overcome the oppression they faced. While the mentors could inform the mentees about some organizational culture differences unknown to the mentees, which has proven valuable, their mentors were unable to offer helpful insight regarding the unique challenges Black females encounter within these cultures. For some participants, their crossrace mentor would avoid the conversation or would focus on something else. This broaching style was highlighted in Carroll and Barnes' (2015) study stated that avoidant strategies tend to serve as a barrier that hinders mentees' success. However, for the participants in this study, the avoidant broaching style did not create a barrier that hindered their success, and participants accepted that their race issues were not topics that their cross-race mentor could advise them on. Fortunately, the participants found that at least some of their mentors recognized this deficiency and actively sought to make connections with others who could provide them mentoring in those areas. This infusing broaching style was also highlighted by Carroll and Barnes (2015), in which the mentor attempts to actively eliminate oppression and promote social justice. These connections made by participants' mentors were from other professionals they knew and included recommended conferences, programs, and institutes that focused on Black women leaders.

Overall, these participants revealed that as Black women in higher education leadership, they are not disadvantaged when seeking meaningful, beneficial, and to some extent relatable mentoring relationships because their true needs for success and climbing the leadership ladder in higher education far exceeds the relation to an individual based solely on race and gender. Although challenges did arise in the mentoring relationships, all participants attested to the positive impact they made in their careers and their ability to overcome those trials, which made them stronger and more capable leaders.

\section{RECOMMENDATIONS FOR FUTURE RESEARCH}

The results of this phenomenological study are similar to those of prior studies; however, they are unique in combining the lived experiences of a select group of Black women in higher education leadership and the use of cross-race and cross-gender mentorship. This study contributes to the 
literature in that it not only examines mentorship broadly defined but also Black women's experiences with mentorship, specifically cross-race only, cross-gender only, and/or both types of mentorship. The findings in this study are consistent with what is known about mentorship and that regardless of race and/or gender, mentorship is a useful tool that is used to promote growth (Davis \& Maldonado, 2015; Johnson \& Ridley, 2018; Penny \& Gaillard, 2006; Shea, 1994), enhance leadership skills (Davis \& Maldonado, 2015; Hill \& Wheat, 2017; Kutchner \& Kleschick, 2016), and is especially important for career advancement (Davis \& Maldonado, 2015; Gardner et al., 2014; Tran, 2014). Current research is more limited in the understanding and application of mentorship for Black women in higher education leadership (Bartman, 2015; Penny \& Gaillard, 2006), which was addressed by this study. Given the critical need to not only diversify top leadership positions in higher education but also connect with its diverse student population, additional studies should focus on examining both the lived experiences of diverse mentees and mentors. Additionally, future studies should examinethe leadership style of mentors who also serve as supervisors, which is a possiblecontributor for the mentee's selection process. Participants in this study revealed an attraction to their mentors' personable personality, which correlates, in my opinion, to charismatic leadership. The exploration of a mentor's leadership style can yield a deeper understanding of mentoring pairing and leadership development of the mentee.

As this study only focused on utilizing Black women in academia, future studies can examine lived experiences of Black women leaders in government, business, and medical sectors, as well as K-12 education, to expand the literature that focuses on Black women leaders and mentorship. Their experiences can also provide rich data about their mentoring experiences, including behaviors and practices, selection and identification of mentors, and features and characteristics deemed beneficial or detrimental to their careers and the mentoring relationship. Based on the results from this study, future research can build upon the findings with a large quantitative study to test, and possibly confirm, what has been presented. By examining a broader selection of Black women in different professions and increasing the number of participants, this might lead to more generalizable findings.

Lastly, examining the lived experiences of Black female college students (e.g., undergraduate and graduate students) and their experiences with cross-race and cross-gender mentorship will add to the much-needed literature that highlights the nature of mentorship, outside of sororities, family and church members, and friends (Crawford \& Smith, 2005), while seeking a college degree.Bartman (2015) called for such a study, stating that although Black female students have achieved success academically, their success has overshadowed the crucial need for effective mentorship approaches that are designed to promote their continued development and achievement in all aspects of their higher education experience and beyond.

\section{Recommendations for Professional Practice}

Creating a culture of diversity and inclusion can be addressed by many professional practices by implementing programs that emphasize mentorship. Careful consideration should be at the forefront of the pairing process, including the gathering of detailed information from both the mentor and mentee that will highlight strengths, weaknesses, desired characteristics, career paths and goals, personality traits, work ethic, desired outcomes, personal values, and communication style (Johnson \& Ridley, 2018). As stated by Johnson and Ridley (2018), "Mentorships that are poorly matched in these areas are sometimes doomed to fail. For instance, the mentor will be frustrated by the mentee's lack of ambition, or the mentee may find the mentor too complacent or relaxed" (pp. 107-108). The pairing process is the most crucial component that can impact the relationship both positively and negatively.

Practitioners might use this study to increase their cultural competence and engage in training and conversations that produce awareness regarding all racial groups. According to Johnson and Ridley (2018), "Sometimes mentors [and mentees] hesitate or even avoid entering into mentorships with mentees [or mentors] from other cultures. They fear they lack the competence to mentor [or be mentored] across cultures, or, worse, they fear appearing to be culturally incompetent" (p. 140). In order for cross-race mentoring to be effective, it is imperative for the mentors and mentees to be active learners in the process and have a holistic understanding of racial, ethnic, and cultural identities (Chan et al., 2015). 
In addition to cultural competence, mentors and mentees need to "appreciate and honor gender differences" (Johnson \& Ridley, 2018, p. 147). Particularly, male practitioners should disregard any implicit biases and misperceptions that society has embedded about men working with women. As stated by Johnson and Ridley (2018),

What's the solution? Exposure! Rather than quarantine women from male mentorship for fear of rumors, attraction, or making a misstep, men need to initiate more interaction and mentorship with women. Mere exposure, sincere gender humility, and a learning orientation will work wonders in lowering anxiety. And here's an insider note to men: if you mentor women often and deliberately, you benefit as well. Evidence suggests that not only can the mentorship make a huge difference in your career, it can improve your own emotional intelligence, communication skill set, and professional network. To tell the truth, you'll probably also become a better partner, husband, and friend-in a word, an all-around better man. (p. 149)

Men and women should approach cross-gender mentorship with an openmind and the will to overcome the challenges that will arise due to gender differences. However, avoiding cross-gender mentorship is not the approach to take when constructing change that will increase diversity and inclusion in the workplace.

\section{CONClusions}

The purpose of this phenomenological study was to examine the lived of experiences of a select group of Black women leaders in higher education who have had experience with cross-race, cross-gender, and/or both types of mentors. Eight participants revealed their utilization of cross-race only and/or cross-gendermentorship and its impact on their career and leadership position. Participants made it clear that their unique mentoring pairing/selection was not determined solely by race or gender, but by certain qualities and characteristics that they desired in a mentor. Although these mentoring relationships evolved organically due to the dual role of the identified mentors, participants revealed that these mentoring relationships did not flourish overnight and were not without challenges, uncertainties, and difficult situations. Intersectionality influenced some of the interactions between participants and their mentors, but these challenges were not strong enough for the participants to dissolve the mentoring relationships. Additionally, participants revealed the struggles they faced while highlighting the difficulties in reducing the intersection of race and gender, which proved Collins' (2000) assertion that regardless of where Black women reside, who they are, and what their title is, they experience intersecting oppressions that produces similar results. The participants stressed the importance of having a mentor with the ability to guide, advocate, and sponsor; provide network and exposure opportunities; who is open, honest, transparent, trustworthy, personable, supportive and willing to invest, accessible, and able to connect with a mentee based on principles that they deemed to be important. Understanding mentoring experiences for Black women and the intersection of race and gender provides an understanding of the impact a mentor has, or does not have, in mentees' climb up the leadership ladder.

\section{REFERENCES}

Alinia, M. (2015). On Black feminist thought: Thinking oppressions and resistance through intersectional paradigm. Ethnic and Racial Studies, 38(13), 2334-2340.https://doi.org/10.1080/01419870.2015.1058492

Bartman, C. (2015). African American women in higher education: Issues and support strategies. College Student Affairs Leadership,2(2).https://scholarworks.gvsu.edu/cgi/viewcontent.cgi?article=1020\& context $=$ csal

Beckwith, L. Carter, D., \& Peters, T. (2016). The underrepresentation of African American women in executive leadership: What's getting in the way? Journal of Business Studies Quarterly, 7,(4), 115-134.

Boswell, J., Stark, M., Wilson, A., \& Onwuegbuzie, A. (2017). The impact of dual roles in mentoring relationships: A mixed research study. Journal of Counselor Preparation and Supervision, 9(2), 1-27. https://repository.wcsu.edu/cgi/viewcontent.cgi?article=1175\&context=jcps

Bova, B. (1998). Mentoring revisited: The African-American woman's experience. Mentoring \&Tutoring, 8, 516. https://doi.org/10.1080/713685511

Brown, T. (2005). Mentorship and the female college president. Sex Roles, 52(9/10), 659-666. https://10.1007/ s11199-005-3733-7 
Black Women in Higher Education Leadership: A Phenomenological Research Study Examining Their Utilization of Cross-Race and Cross-Gender Mentorship

Carroll, M., \& Barnes, F. (2015). Strategies for enhancing diverse mentoring relationships in STEM fields. International Journal of Evidence Based Coaching and Mentoring, 13, 58-69. http://ijebcm.brookes.ac.uk/ documents/vol13issue1-paper-04.pdf

Chan, A., Yeh, C., \& Krumboltz, J. (2015). Mentoring ethnic minority counseling and clinical psychology students: A multicultural, ecological, and relational model. Journal of Counseling Psychology, 62(4), 592607. https://dx.doi.org/10.1037/cou0000079

Collins, P. (2000). Black feminist thought: Knowledge, consciousness, and the politics of empowerment $\left(2^{\text {nd }}\right.$ ed.). Routledge.

Collins, P., \& Bilge, S. (2016). Intersectionality: Key concepts. Polity Press.

Commodore, F., Freeman, S., Gasman, M., \& Carter, C. (2016). "How it's done:" The role of mentoring and advice in preparing the next generation of historically black college and university presidents. Education Sciences, 6(19), 1-14. https://doi.org/10.3390/educsci6020019

Cox, T., \& Nkomo, S. (1991). A race and gender group-analysis of the early career experiences of MBAs. Work and Occupations, 18(4), 431-446. https://doi.org/10.1177/0730888491018004004

Crawford, K., \& Smith, D. (2005). The we and the us: Mentoring African American women. Journal of Black Studies, 36, 52-67. https://doi.org/10.1177/0021934704265910

Crenshaw, K. (1989). Demarginalizing the intersection of race and sex: A black feminist critique of antidiscrimination doctrine, feminist theory and antiracist politics. University of Chicago Legal Forum, 1989(8), 139-167. https://chicagounbound.uchicago.edu/uclf/vol1989/iss1/8

Creswell, J. W., \& Poth, C. N. (2018). Qualitative inquiry and research design: Choosing among five approaches $\left(4^{\text {th }}\right.$ ed.). Sage.

Cross, M., Lee, S., Bridgman, H., Thapa, D., Cleary, M., \& Kornhaber, R. (2019). Benefits,barriers, and enablers of mentoring female health academics: An integrative review. PLOS One, 14(4), 1-21. https://doi.org/10.1371/journal.pone.0215319

Curtin, N., Malley, J., \& Stewart, A. (2016). Mentoring the next generation of faculty:Supporting academic career aspirations among doctoral students. Research in HigherEducation, 57(6), 714-738. https://doi.org /10.1007/s11162-015-9403-x

Davis, A. (2009). Empowering African American women in higher education throughmentoring. Journal of the National Society of Allied Health, 6(7), 53-58.

Davis, D. R. \& Maldonado, C. (2015). Shattering the glass ceiling: The leadershipdevelopment of African American women in higher education. Advancing Women in Leadership, 35, 48-64.http://www. advancingwomen.com/awl/Vol35_2015/Davis_Shattering_the_Glass_Ceiling.pdf

Englander, M. (2012). The interview: Data collection in descriptive phenomenological humanscientific research. Journal of Phenomenological Psychology, 43, 13-35. https://doi.org/10.1163/156916212x632943

Evans, G., \& Cokley, K. (2008). African American women in the academy: Using careermentoring to increase research productivity. Training and Education in Professional Psychology, 2, 50-57. https://doi.org/ 10.1037/1931-3918.2.1.50

Evans, L. (2019). Supervisors as mentors. College \& Research Libraries News, 80(7), 403-405. https://doi.org/10.5860/crln.80.7.403

Gagliardi, J., Espinosa, L., Turk, J., \& Taylor, M. (2017). American college president study2017 (Research Report No. 8). American Council on Education. https://www.acenet.edu/Research-Insights/Pages/ American-College-President-Study.aspx

Gardner, L., Barrett, T., \& Pearson, L. (2014). African American administrators at PWIs:Enablers of and barriers to career success. Journal of Diversity in Higher Education, 7(4),235-251. https://doi.org/ $10.1037 / \mathrm{a} 0038317$

Gasman, M., Abiola, U., \& Travers, C. (2015). Diversity and senior leadership at eliteinstitutions of higher education. Journal of Diversity in Higher Education, 8, 1-14.https://doi.org/10.1037/a0038872

Grant, C. (2012). Advancing our legacy: A Black feminist perspective on the significance of mentoring for African American women in educational leadership. International Journalof Qualitative Studies in Education, 25, 99-115. https://doi.org/10.1080/09518398.2011.647719

Grant, C., \& Ghee, S. (2015). Mentoring 101: Advancing African-American women faculty and doctoral student success in predominantly White institutions. International Journal of Qualitative Studies in Education, 28(7), 759-785. https://doi.org/10.1080/09518398.2015.1036951

Groenewald, T. (2004). A phenomenological research design illustrated. International Journal ofQualitative Methods, 3, 42-55. https://doi.org/10.1177/160940690400300104 
Hague, L., \& Okpala, C. (2017). Voices of African American women leaders on factors thatimpact their career advancement in North Carolina community colleges. Journal of Research Initiatives, 2(3), 19.https://digitalcommons.uncfsu.edu/cgi/viewcontent.cgi?article=1122\&context=jri

Hardcastle, B. (1988). Spiritual connections: Protégés' reflections on significant mentorships. Theory into Practice, 27(3), 201-208. https://doi.org/10.1080/00405848809543352

Hill, L., \& Wheat, C. (2017). The influence of mentorship and role models on university womenleaders career paths to university presidency. Qualitative Report, 22(8), 2090-2111. https://nsuworks.nova.edu/tqr/ vol22/iss $8 / 2$

Humberd, B., \& Rouse, E. (2016). Seeing you in me and me in you: Personal identification in thephases of mentoring relationships. Academy of Management Review, 41(3), 435-455.https://doi.org/10.5465/ amr.2013.0203

Ivankova, N. V. (2015). Mixed methods applications in action research: From methods tocommunity action.Sage.

Johnson, J., \& Snider, J. (2015). PhorwarD progress: Moving ahead through mentorship in theacademy. In B. L. Marina (Ed.), Mentoring away the glass ceiling in academia: Acultured critique (pp. 3-16). Lexington Books.

Johnson, W., \& Ridley, C. (2018). The elements of mentoring ( $3^{\text {rd }}$ ed.). St.Martin's Press.

Kent, A., Green, A., \& Feldman, P. (2015). The road less traveled-cross gender and racial linesin comprehensive mentoring. International of Journal of Education Research, 72, 116-128.https://doi.org/10.1016/j.ijer. 2015.06.003

Kutchner, W., \& Kleschick, P. (2016). Mentoring in higher education. College \& University,91(4), 41-46.

Lewis, J., Williams, M., Peppers, E., \& Gadson, C. (2017). Applying intersectionality to explore the relations between gendered racism and health among Black women. Journal of Counseling Psychology, 64(5), 475486. https://doi.apa.org/doi/10.1037/cou0000231

Lim, L., Clarke, A., Ross, F., \& Wells, J. (2015). Mentoring experiences, perceived barriers, andimpact on current job positions for African American Accountants. Advancing Women inLeadership, 35, 193203.https://doi.org/10.18738/awl.v35i0.135

Mapp, T. (2008). Understanding phenomenology: The lived experience. British Journal of Midwifery, 16(5), 308-311.

Meeuwissen, S., Stalmeijer, R., \& Govaerts, M. (2019). Multiple-role mentoring: Mentors' conceptualisations, enactments and role conflicts. Medical Education, 53(6), 605-615. https://doi.org/10.1111/medu.13811

Miles, S. (2012). Left behind: The status of Black women in higher education administration[Doctoral dissertation, Florida State University]. Florida State University Libraries. https://diginole.lib.fsu.edu/ islandora/object/fsu:183012/datastream/PDF/view

Mondisa, J. (2014, June 15-18). Mentoring minorities: Examining mentoring from a race and gender lens [Paper presentation]. $121^{\text {st }}$ ASEE Annual Conference \& Exposition, Indianapolis, IN.

Moradi, B., \& Grzanka, P. (2017). Using intersectionality responsibly: Toward criticalepistemology, structural analysis, and social justice activism. Journal of Counseling Psychology, 64(5), 500-513.https:// doi.org/10.1037/cou0000203

Moustakas, C. (1994). Phenomenological research methods. Sage.

National Center for Education Statistics. (2017). Degrees conferred. United States Department of Education. Retrieved October 2017 fromhttps://nces.ed.gov/programs/raceindicators/indicator_re.asp

Neubauer, B., Witkop, C., \& Varpio, L. (2019). How phenomenology can help us learn from the experiences of others. Perspectives on Medical Education, 8, 90-97. https://doi.org/10.1007/s40037-019-0509-2

Palmer, G., \& Johnson-Bailey, J. (2008). The impact of mentoring on the careers of African Americans. Canadian Journal of Career Development, 7, 45-51.http://cjcdonline.ca/wp-content/uploads/2014/11/TheImpact-of-Mentoring-on-the.pdf

Pan, W., Sun, L., \& Chow, I. (2011). The impact of supervisory mentoring on personal learning and career outcomes: The dual moderating effect of self-efficacy. Journal of Vocational Behavior, 78(2), 264-273. https://doi.org/10.1016/j.jvb.2010.05.001

Patton, L., \& Harper, S. (2003). Mentoring relationships among African American women in graduate and professional schools. New Directions for Student Services, 2003(104), 67-78.https://doi.org/10.1002/ss. 108

Patton, M. Q. (2015). Qualitative research \& evaluation methods (5th ed.). Sage.

Penny, J., \& Gaillard, L. (2006). Mentoring African American women in higher education administration, Gender, Race, \& Class, (13)1-2, 191-200.https://www.jstor.org/stable/41675232 
Black Women in Higher Education Leadership: A Phenomenological Research Study Examining Their Utilization of Cross-Race and Cross-Gender Mentorship

Rubin, H., \& Rubin, I. (2012). Qualitative interviewing: The art of hearing data (3rd ed.).Sage.

Sanchez-Hucles, J., \& Davis, D. (2010). Women and women of color in leadership: Complexity,identity, and intersectionality. American Psychological Association, 63(3), 171-181. https://doi.org/10.1037/a0017459

Scanlon, K. (1997). Mentoring women administrators: breaking through the glass ceiling. Initiatives, 58(2), 3959.

Searby, L., Ballenger, J., \& Tripses, J. (2015). Climbing the ladder, holding the ladder: Thementoring experiences of higher education female leaders. Advancing Women in Leadership, 35, 98107.https://doi.org/10.18738/awl.v35i0.141

Shea, G. (1994). Mentoring: Helping employees reach their full potential. American Management Association.

Smith, J., Flowers, P., \& Larkin, M. (2009). Interpretative phenomenological analysis:Theory, method and research.Sage.

Steinmetz, K. (2020, March 2). Q+A: Kimberlè Crenshaw. TIME Magazine, 195(7/8), 82.

Stitt, R., \& Happel-Parkins, A. (2019). "Sounds like something a White man should be doing:" The shared experiences of Black women engineering students. Journal of Negro Education, 88, 62-74. https:// 10.7709/jnegroeducation.88.1.0062

Tran, N. A. (2014). The role of mentoring in the success of women leaders of color in higherEducation. Mentoring \& Tutoring: Partnership in Learning, (22)4, 302-315. https://doi.org/10.1080/1361 1267.2014.945740

Walkington, L. (2017). How far have we really come? Black women faculty and graduatestudents' experiences in higher education. Humboldt Journal of Social Relations, 39, 51-65.https://www.jstor.org/ stable/90007871

Wilson, D. \& Washington, G. (2007). Retooling phenomenology: Relevant methods for conducting research with African American women. Journal of Theory Construction \& Testing, 11(2), 63-66.

Wright, D., \& Salinas. C. (2017). African American women leaders in higher education. Advances in Educational Administration, 25, 91-105.https://doi.org/10.1108/S1479-366020160000025006

\section{AUTHOR'S BIOGRAPHY}

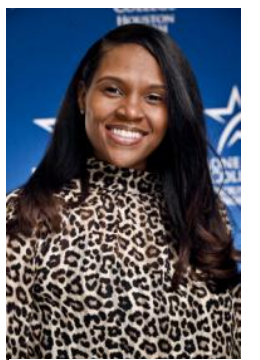

Dr. Jerica C. Nickerson-Guidry, a department chair, professor of speech, and faculty fellow at Lone Star College-Houston North, is, first and foremost, a wife and mother of two beautiful children. As a life-long learner, she truly believes that at its core, education is the gateway to experiencing a purposeful life. She received her Bachelor of Science degree in Psychology from the University of Houston. Soon after that, Dr. Nickerson-Guidry pursued a Master of Arts degree in Communication from Texas Southern University and completed her doctorate degree in Organizational Leadership with a concentration in Higher Education from Abilene Christian University. Dr. Nickerson-Guidry's professional interest includes mentorship, as she believes that proper mentorship is one of the most crucial and influential components for career and educational development.

Citation: Dr. Jerica C. Nickerson-Guidry. "Black Women in Higher Education Leadership: A Phenomenological Research Study Examining Their Utilization of Cross-Race and Cross-Gender Mentorship” International Journal of Humanities Social Sciences and Education (IJHSSE), vol 8, no. 10, 2021, pp. 75-93. doi: https://doi.org/10.20431/2349-0381.0810009.

Copyright: (C) 2021 Authors. This is an open-access article distributed under the terms of the Creative Commons Attribution License, which permits unrestricted use, distribution, and reproduction in any medium, provided the original author and source are credited. 